\title{
Development of lab scale pineapple fruit juicer
}

\author{
Somnath D. Savalkar, K.P. Babar and D.T. Bornare
}

Received : 21.05.2018; Revised : 13.08.2018; Accepted : 28.08.2018

See end of the Paper for authors' affiliation

Correspondence to :

Somnath D. Savalkar Department of Agricultural Engineering, Maharashtra Institute of Technology, Aurangabad (M.S.) India Email : somnathsavalkar@ gmail.com
- ABSTRACT : Pineapple is the third most important tropical fruit in the world after banana and citrus fruit. This fruit is highly perishable and seasonal.Juice extraction is the process by which the liquid potion of the fruit is been squeezed or forced out of the solid part of the fruit either by manual or mechanical.Automatic pineapple juicer machine can do all the process required to produce the pineapple juice that means core of the pineapple can be crushing by the machine and the pomace and juice is separated differently. In this machine we firstly cut the fruit by using rotating knife and these fruit cubes are passed through squeezing mechanism in this screw shaft rotating and juice separate and pomace are separate. In this determination of physical properties like dimensions (Length, Width, Thickness), Geometric mean diameter, sphericity, size shape, surface area and density were determined. Average length, width and thickness were $164.8 \mathrm{~mm}$, $87.12 \mathrm{~mm}$ and $88.9 \mathrm{~mm}$, respectively. Average weight of pineapple fruit was $898.8 \mathrm{~g}$. Size, shape, density and sphericity of pineapple fruit were 109.68, 53.38, 1.394 and 0.64 , respectively. The average is taken the weight of fruit $(\mathrm{g})$, weight of waste (g), weight of juice (g) are 1191.5, 318.6 and 826.1 , respectively. On this observation we come to know that juice yield (\%), extraction efficiency (\%), extraction loss (\%), are 71.09, 70.15, and 3.91were taken, respectively. The RPM is 2800. Powered by a $0.35 \mathrm{HP}$ single phase electric motor, the machine has a capacity of $18.90 \mathrm{~kg} / \mathrm{h}$.

- KEY WORDS : Fruit juice, Juice extractor, Physical properties, Pineapple, Pomace

- HOW TO CITE THIS PAPER : Savalkar, Somnath D., Babar, K.P. and Bornare, D.T. (2018). Development of lab scale pineapple fruit juicer. Internat. J. Agric. Engg., 11(2) : 320-323, DOI: 10.15740/HAS/IJAE/11.2/320-323. Copyright@2018: Hind Agri-Horticultural Society. 